\title{
Dor em crianças e adolescentes com doença falciforme: estudo observacional
}

\author{
Pain in children and adolescents with \\ falciform disease: observational study
}

\author{
Rosicleide Araújo Freitas Machado ${ }^{1}$ (1) \\ Andréia Gonçalves Batista Lima ${ }^{2}$ (1) \\ Hana Silva Almeida ${ }^{3}$ (1) \\ Alana Sousa Santos de Carvalho ${ }^{4}$ (1) \\ Katia Nunes Sá5
}

\author{
1-4Escola Bahiana de Medicina e Saúde Pública (Salvador). Bahia, Brasil. rafmsalvador@bahiana.edu.br, andreiagobat@gmail.com, \\ hanaalmeida18.2@bahiana.edu.br, alanascarvalho16.2@bahiana.edu.br \\ ${ }^{5}$ Autora para correspondência. Escola Bahiana de Medicina e Saúde Pública (Salvador). Bahia, Brasil. katia.sa@gmail.com
}

\begin{abstract}
RESUMO | INTRODUÇÃO: O sintoma mais comum na Doença Falciforme (DF) é a dor de alta intensidade que se manifesta desde a infância. Para ser controlada, é necessária a determinação do seu tipo. OBJETIVO: Delinear o perfil da dor em crianças e adolescentes com doença falciforme e analisar o impacto do tipo desta na qualidade de vida. METODOLOGIA: Estudo transversal realizado com crianças e adolescentes com idade entre 8 e 17 anos e diagnóstico de DF HbSS e HbSC (critérios da OMS), em unidades de referência (Salvador, Bahia, Brasil). Foram aplicados a escala infantil de avaliação de dor Adolescent Pediatric Tool (APPT) e o questionário de qualidade de vida PedsQL módulo DF. Foram testadas associações e correlações entre os itens dos instrumentos (Alfa 5\%, Beta 20\%). CAAE 57274516.8.0000.5544 e 09163419.3.0000.5544. RESULTADOS: Duas amostras, uma com 46 e outra com 44 participantes, com cerca de $60 \%$ do tipo HbSS, confirmaram presença de alta intensidade da dor (de 5,0 0 0,00 a 9,94 $\pm 0,23$ pontos na escala de intensidade de dor) por todo o corpo e uso sistemático de analgésicos (95,5\%). Quanto maior a intensidade da dor, principalmente no caso da dor neuropática, maior o total de descritores e o uso de termos sensoriais, afetivos e temporais $(p<0,05)$, com correlações fortes $(r \geq$ $0,84 ; p<0,05)$ entre intensidade e descritores sensoriais e avaliativos. CONCLUSÃO: A dor em crianças e adolescentes com DF apresenta alta intensidade, com os piores prejuízos para os que referem dor com características neuropáticas.
\end{abstract}

PALAVRAS-CHAVE: Anemia Falciforme. Dor. Criança. Adolescente. Qualidade de Vida.

\begin{abstract}
INTRODUCTION: The most common symptom in sickle cell disease (SCD) is high-intensity pain that manifests in childhood. To be controlled, it is necessary to determine its type. OBJECTIVE: To outline the profile of pain in children and adolescents with sickle cell disease and analyze its impact on quality of life. METHODS: Cross-sectional study was con-ducted with children and adolescents aged 8 to 17 years and diagnosed with DF HbSS and HbSC (WHO criteria) in reference units (Salvador, Bahia, Brazil). The Adolescent Pediatric Tool (APPT) children's pain assessment scale and the PedsQL module DF quality of life questionnaire were applied. Associations and correlations between the items of the instruments were tested (Alpha 5\%, Beta 20\%). CAAE 57274516.8.0000.5544 and 09163419.3.0000.5544. RESULTS: Two samples, one with 46 and the other with 44 partici-pants, with about $60 \%$ of the HbSS type, confirmed the presence of high pain intensity (from $5.0 \pm 0.00$ to $9.94 \pm 0.23$ points on the scale pain intensity) throughout the body and systematic use of analgesics (95.5\%). The greater the intensity of pain, especially in the case of neuropathic pain, the greater the total number of descriptors and the use of sensory, affective, and temporal terms $(p<0.05)$, with strong correlations $(r \geq$ $0.84 ; p<0,05$ ) between intensity and sensory and evalua-tive descriptors. CONCLUSION: Pain in children and adolescents with SCD is high intensity, with the worst losses for those who report pain with neuropathic characteristics.
\end{abstract}

KEYWORDS: Sickle Cell Anemia. Pain, Child. Adolescent. Quality. 


\section{Introdução}

A Doença Falciforme (DF) é a doença hematológica hereditária mais prevalente no mundo, ela provoca alterações físicas, psicológicas, sociais e econômicas nos acometidos. ${ }^{1}$ Cerca de $7 \%$ da população mundial apresenta traços ou anemias relacionadas às hemoglobinas HbSS, HbSC, HbSD e HbSE.? Estima-se uma incidência de DF nos Estados Unidos de um a cada 350 nascidos vivos entre os afrodescendentes. ${ }^{3}$ Estimam que nascem cerca de 3.500 crianças por ano com DF no Brasil, sendo a região do recôncavo baiano o local com maior número de casos novos (taxa de 1:314 nascidos vivos). ${ }^{4}$

Pessoas com DF, em algum momento da vida, experimentarão a desagradável experiência da crise álgica relacionada à vaso oclusão que é responsável por frequentes internações e elevado nível de sofrimen-

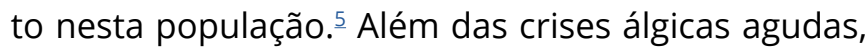
pessoas com DF também referem presença de Dor Crônica (DC), com frequência diária ou quase diária, como a característica mais marcante da doença..${ }^{6} \mathrm{~A}$ DC é em si uma morbidade complexa e multidimensional que exige abordagem interdisciplinar. $\underline{?}$

Boa parte da DC na DF tem sido classificada como uma dor do tipo neuropática com envolvimento de disfunções no sistema somato-sensorial, ou consequente de uma sensibilização central.. A dor do tipo neuropática tem intensidade maior, não responde bem aos analgésicos comuns, é mais difícil de ser controlada e provoca perdas importantes na qualidade de vida dos acometidos. .9 No entanto, muitas dores podem ser nociceptivas devido à isquemia local, e após a crise, são remissíveis. Dores neuropáticas e nociceptivas respondem a condutas totalmente distintas ${ }^{10}$, exigindo dos clínicos uma avaliação precisa.

Existem relatos de manifestação de dor afetando crianças com DF desde os seis meses de vida. ${ }^{11}$ Como o sistema nervoso ainda está em formação na infância e adolescência, a presença de dor sem o controle adequado pode gerar uma plasticidade mal adaptativa. Essa disfunção cerebral pode, por sua vez, perpetuar a dor por toda a vida. No entanto, poucos estudos delinearam a dor em crianças e adolescentes e avaliaram seu impacto sobre a qualidade de vida, especialmente em local com tão alta incidência como a Bahia. ${ }^{12} \mathrm{O}$ objetivo do presente estudo foi delinear o perfil da dor em crianças e adolescentes com doença falciforme, e avaliar o impacto do tipo de dor na qualidade de vida desta população.

\section{Metodologia}

Estudo transversal, quantitativo e analítico, com dados primários, realizado de março de 2017 a julho de 2019 em unidades de referência para o acompanhamento de pessoas com DF em Salvador, Bahia, Brasil. A equipe responsável pela coleta envolveu três enfermeiras e uma acadêmica de enfermagem, devidamente treinadas. Os dados foram obtidos em duas coletas complementares em que ambos os projetos foram aprovados pelo comitê de ética em pesquisa envolvendo seres humanos da Escola Bahiana de Medicina e Saúde Pública sob os números de CAAE 57274516.8.0000.5544 e 09163419.3.0000.5544. Todas as recomendações do Conselho Nacional de Saúde e da resolução 466/12, foram seguidas com rigor.

Foram incluídos crianças e adolescentes com idade entre 8 e 17 anos, de ambos os sexos, com diagnóstico confirmado de DF nos genótipos HbSS e HbSC segundo os critérios da Organização Mundial de Saúde (OMS), cujos responsáveis legais tenham assinado o termo de consentimento livre e esclarecido, e os menores, o termo de assentimento livre e esclarecido. Foram excluídos os que apresentaram comorbidades confundidoras, como artrite reumatoide juvenil, traumas e outras inflamações há menos de quinze dias.

Os instrumentos aplicados foram a escala Adolescent Pediatric Pain Tool (APPT-P Brasil) ${ }^{13}$ para avaliar o local, a intensidade e os descritores para a dor; e o PedsQL módulo DF para avaliar a Qualidade de Vida Relacionada à Saúde cujo uso foi previamente autorizado pelo Mapi Research Trust (http://www.mapi-trust. org/). Todas as recomendações dos desenvolvedores dos referidos instrumentos foram seguidas. Devido a inexistência de um instrumento capaz de distinguir o tipo de dor em pessoas nesta faixa etária, os descritores da APPT-p Brasil semelhantes aos utilizados pelo Doleur Neuropathic Pain DN-4 ${ }^{14}$ foram usados para a classificação da dor neuropática. 
Os dados foram tabulados e analisados com auxílio do Social Package for Social Science (SPSS versão 14 para Windows). Dados quantitativos foram apresentados com medidas de tendência central e dispersão, e as variáveis categóricas em números absolutos e proporções. Para testar a hipótese se a intensidade da dor se relacionava com os descritores da APPT-P Brasil, foi aplicado o teste Kruskall-Wallis. Para testar a hipótese se o tipo de doença ( $\mathrm{HbSS}$ ou HbSC) se relacionam com a localização e frequência da dor, foi aplicado o teste Qui-quadrado; e com a intensidade da dor, o Mann-Whitney. Os mesmos testes foram usados para comparar o grupo que apresentava dor com características neuropáticas com os demais. Foi ainda avaliada a correlação de Spearman para comparar os descritores com os domínios da qualidade de vida nos diferentes tipos de dor. Todos os testes adotaram o poder de $80 \%$ e a significância de $5 \%$.

\section{Resultados}

Para a primeira parte da análise, a amostra contou com 46 crianças e adolescentes, enquanto a segunda avaliou o impacto na qualidade de vida em 44 participantes (Figura 1).

Figura 1. Fluxograma da primeira parte da análise

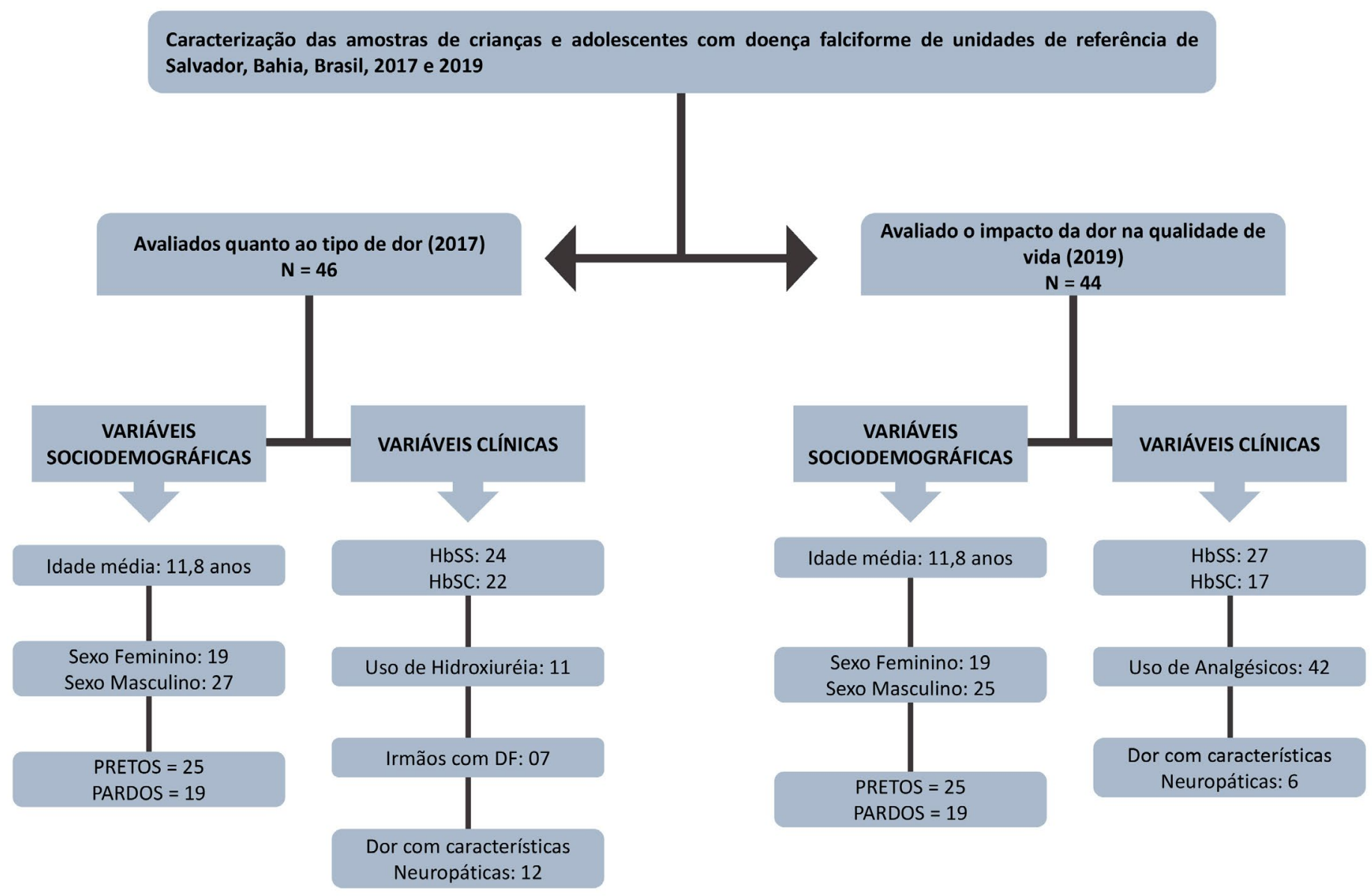


Os dados demográficos e clínicos das duas amostras estão descritos na Tabela 1.

Tabela 1. Caracterização das amostras de crianças e adolescentes com doença falciforme de unidades de referência de Salvador, Bahia, Brasil, 2017 e 2019

\begin{tabular}{|c|c|c|}
\hline \multicolumn{3}{|c|}{ Avaliados quanto ao tipo de dor N = 46 (2017) } \\
\hline Variáveis Sociodemográficas & $\mathbf{N}$ & $\%$ \\
\hline Sexo Masculino & 27 & 58,7 \\
\hline Cor da Pele Autorreferida como Preta & 25 & 54,3 \\
\hline \multirow[t]{2}{*}{ Cor da Pele Autorreferida como Parda } & 19 & 41,3 \\
\hline & M & DP \\
\hline Idade & 11,8 & 2,30 \\
\hline Variáveis Clínicas & $\mathbf{N}$ & $\%$ \\
\hline HbSS & 24 & 52,2 \\
\hline $\mathrm{HbSC}$ & 22 & 47,8 \\
\hline Uso de Hidroxiuréia & 11 & 23,9 \\
\hline Irmãos com DF & 7 & 13,0 \\
\hline Dor com Características Neuropáticas & 12 & 26,1 \\
\hline \multicolumn{3}{|c|}{ Avaliado o impacto da dor na qualidade de vida $\mathrm{N}=44$ (2019) } \\
\hline Variáveis sociodemográficas & $\mathbf{N}$ & $\%$ \\
\hline Sexo Masculino & 25 & 56,8 \\
\hline Cor da Pele Autorreferida como Preta & 25 & 54,3 \\
\hline \multirow[t]{2}{*}{ Cor da Pele Autorreferida como Parda } & 19 & 41,3 \\
\hline & M & DP \\
\hline Idade & 11,8 & 2,73 \\
\hline Variáveis Clínicas & $\mathbf{N}$ & $\%$ \\
\hline HbSS & 27 & 61,4 \\
\hline $\mathrm{HbSC}$ & 17 & 38,7 \\
\hline Uso de Analgésicos & 42 & 95,5 \\
\hline Dor com Características Neuropáticas & 6 & 13,6 \\
\hline
\end{tabular}

A intensidade da dor foi de média $(5,00 \pm 0,00)$ a severa $(9,94 \pm 0,23)$ de acordo com os pontos da escala visual de dor da APPT. Quanto maior a intensidade, mais descritores foram utilizados pelos participantes. A intensidade da dor $(p<0,001)$, o número total de descritores $(p=0,003)$, o descritor afetivo $(p=0,034)$ e o descritor avaliativo $(p<0,001)$ da APPT se relacionaram com a intensidade "pior dor" categorizada em três estratos, Tabela 2.

Tabela 2. Variáveis contínuas relacionadas à intensidade da dor em crianças e adolescentes com anemia falciforme, Salvador, Bahia, Brasil, 2017

\begin{tabular}{|c|c|c|c|c|}
\hline & $\begin{array}{l}\text { Dor } \\
\mu \pm \sigma\end{array}$ & $\begin{array}{l}\text { Muita } \\
\mu \pm \sigma\end{array}$ & $\begin{array}{l}\text { Pior } \\
\mu \pm \sigma\end{array}$ & P-valor \\
\hline Intensidade da dor & $5,00 \pm 0,00$ & $7,35 \pm 0,44$ & $9,94 \pm 0,23$ & $<0,001$ \\
\hline Total Descritores & $17,73 \pm 5,53$ & $24,50 \pm 8,49$ & $27,78 \pm 7,17$ & 0,003 \\
\hline Descritor Sensorial & $7,91 \pm 3,05$ & $10,63 \pm 5,73$ & $11,94 \pm 5,01$ & 0,132 \\
\hline Descritor Afetivo & $3,82 \pm 2,67$ & $5,38 \pm 1,78$ & $6,28 \pm 1,99$ & 0,034 \\
\hline Descritor Avaliativo & $2,36 \pm 1,20$ & $4,00 \pm 1,63$ & $4,94 \pm 1,06$ & $<0,001$ \\
\hline Descritor temporal & $3,91 \pm 1,30$ & $4,56 \pm 1,83$ & $4,50 \pm 1,98$ & 0,716 \\
\hline
\end{tabular}

Os locais mais acometidos foram as pernas no grupo $\mathrm{HbSS}$ e braços no grupo $\mathrm{HbSC}$. A maior parte refere que a dor os acomete poucas vezes por mês. Não foram identificadas associações significativas entre o tipo de doença e os locais, frequência e intensidade da dor, Tabela 3. 
Tabela 3. Relação entre o tipo de doença e algumas variáveis relacionada à dor em crianças e adolescentes com anemia falciforme, Salvador, Bahia, Brasil, 2017

\begin{tabular}{|c|c|c|c|}
\hline & $\begin{array}{l}\text { SS } \\
N=24\end{array}$ & $\begin{array}{l}S C \\
N=22\end{array}$ & P-valor \\
\hline Localização da dor ${ }^{a}$ & & & 0,079 \\
\hline Abdome & $3(12,5)$ & $4(18,2)$ & NA \\
\hline Braços & $3(12,5)$ & $10(45,5)$ & NA \\
\hline Pernas & $11(45,8)$ & $6(27,3)$ & NA \\
\hline Dorsal & $3(12,5)$ & $0(0,0)$ & NA \\
\hline Articulações & $0(0,0)$ & $1(4,5)$ & NA \\
\hline Tórax & $1(4,2)$ & $0(0,0)$ & NA \\
\hline Lombar & $3(12,5)$ & $1(4,5)$ & NA \\
\hline Frequência da dora & & & 0,068 \\
\hline Quase todos os dias & $1(4,2)$ & $2(9,1)$ & NA \\
\hline Poucos dias da semana & $2(8,3)$ & $1(4,5)$ & NA \\
\hline Poucas vezes no mês & $19(79,2)$ & $11(50,0)$ & NA \\
\hline Sem informação & $2(8,3)$ & $2(9,1)$ & NA \\
\hline Esporádica & $0(0,0)$ & $6(27,3)$ & NA \\
\hline Intensidade da dor & $8,04 \pm 2,07$ & $7,34 \pm 2,12$ & 0,244 \\
\hline
\end{tabular}

A dor com características neuropáticas se associou com o número total de descritores $(p=0,002)$, com os descritores sensoriais $(p<0,001)$, com os afetivos $(p=0,038)$ e com os temporais $(p=0,018)$, Tabela 4 .

Tabela 4. Relação estatística entre dor neuropática e alguns descritores da dor em crianças e adolescentes com doença falciforme, Salvador, Bahia, Brasil, 2017

\begin{tabular}{lccc}
\hline & $\begin{array}{c}\text { Indicador dor } \\
\text { neuropática } \\
\mathrm{N}=12\end{array}$ & $\begin{array}{c}\text { Ausência de indicador de } \\
\text { dor neuropática }\end{array}$ & $\mathrm{N=34}$ \\
\hline Intensidade da dor $^{\mathrm{b}}$ & $7,79 \pm 1,85$ & $7,67 \pm 2,21$ & P-valor \\
Frequência da dor & $\mathrm{NA}$ & $\mathrm{NA}, 969$ \\
Quase todos os dias & $2(16,7)$ & $1(2,9)$ & 0,093 \\
Poucos dias da semana & $0(0,0)$ & $3(8,8)$ & $\mathrm{NA}$ \\
Poucas vezes no mês & $10(93,3)$ & $20(58,8)$ & $\mathrm{NA}$ \\
Sem informação & $0(0,0)$ & $4(11,8)$ & $\mathrm{NA}$ \\
Esporádica & $0(0,0)$ & $6(17,6)$ & $\mathrm{NA}$ \\
Total descritores $^{\mathrm{b}}$ & $31,33 \pm 9,55$ & $21,21 \pm 6,13$ & 0,002 \\
Descritor Sensorial $^{\mathrm{b}}$ & $15,50 \pm 5,52$ & $8,59 \pm 3,41$ & 0,000 \\
Descritor afetivo $^{\mathrm{b}}$ & $6,50 \pm 2,02$ & $4,79 \pm 2,37$ & 0,038 \\
Descritor avaliativo $^{\mathrm{b}}$ & $4,08 \pm 1,56$ & $3,85 \pm 1,74$ & 0,713 \\
Descritor temporal $^{\mathrm{b}}$ & $5,42 \pm 1,83$ & $3,97 \pm 1,58$ & 0,018 \\
\hline
\end{tabular}

avariáveis categóricas expressas em N (\%) e Teste Qui-Quadrado

bVariáveis numéricas expressas pela média e desvio-padrão e Teste Mann-Whitney

NA=não se aplica

Crianças e adolescentes com dor com características neuropáticas apresentaram correlações fortes $(r \geq 0,84)$ com a intensidade da dor $(p=0,015)$, com os descritores sensoriais $(p=0,011)$ e avaliativos $(p=0,034)$ no domínio "Dor e Dano" do PedQV-DF. Os descritores temporais apresentaram correlações fortes com os domínios "Impacto da Dor" ( $p=0,008)$ e módulo I da "Comunicação" $(p=0,013)$. Enquanto os que referiram dor com características nociceptivas apresentaram de moderadas a fracas correlações entre a intensidade da dor e os "Descritores Sensoriais" em praticamente todos os domínios da PedQL-DF, exceto no domínio "Tratamento", Tabela 5. 
Dor com características neuropáticas

\begin{tabular}{|c|c|c|c|c|c|}
\hline & $\begin{array}{l}\text { Intensidade } \\
\text { Dor } \\
r(p) \\
\end{array}$ & $\begin{array}{l}\text { Descritores } \\
\text { Sensoriais } \\
r(p)\end{array}$ & $\begin{array}{l}\text { Descritores } \\
\text { Afetivos } \\
r(p)\end{array}$ & $\begin{array}{l}\text { Descritores } \\
\text { Avaliativos } \\
r(p)\end{array}$ & $\begin{array}{l}\text { Descritores } \\
\text { Temporais } \\
r(p)\end{array}$ \\
\hline Dor e Dano & $-0,899(0,015)$ & $-0,912(0,011)$ & $-0,617(0,192)$ & $-0,845(0,034)$ & $-0,765(0,076)$ \\
\hline Impacto da Dor & $-0,603(0,205)$ & $-0,672(0,144)$ & $-0,235(0,654)$ & $-0,600(0,208)$ & $-0,925(0,008)$ \\
\hline Controle da Dor & $-0,493(0,321)$ & $-0,500(0,312)$ & $-0,164(0,756)$ & $-0,359(0,484)$ & $-0,688(0,131)$ \\
\hline Preocupação I & $-0,377(0,461)$ & $-0,618(0,191)$ & $0,278(0,594)$ & $-0,135(0,798)$ & $-0,588(0,219)$ \\
\hline Preocupação II & $0,471(0,346)$ & $0,328(0,525)$ & $0,501(0,311)$ & $0,394(0,439)$ & $0,134(0,800)$ \\
\hline Emoções & $-0,265(0,612)$ & $-0,448(0,373)$ & $0,235(0,654)$ & $0,000(1,000)$ & $-0,433(0,391)$ \\
\hline Tratamento & $0,377(0,416)$ & $0,265(0,612)$ & $0,463(0,355)$ & $0,338(0,512)$ & $0,235(0,653)$ \\
\hline Comunicação I & $-0,564(0,244)$ & $-0,747(0,088)$ & $-0,317(0,541)$ & $-0,657(0,156)$ & $-0,906(0,013)$ \\
\hline Comunicação II & $-0,308(0,553)$ & $-0,563(0,245)$ & $0,295(0,570)$ & $-0,144(0,786)$ & $-0,625(0,184)$ \\
\hline Func. Físico & $0,058(0,913)$ & $0,029(0,956)$ & $0,154(0,770)$ & $0,169(0,749)$ & $0,441(0,381)$ \\
\hline Func. Emocional & $-0,059(0,912)$ & $-0,164(0,756)$ & $0,736(0,095)$ & $0,394(0,439)$ & $0,000(1,000)$ \\
\hline Func. Social & $-0,339(0,511)$ & $-0,313(0,546)$ & $0,230(0,662)$ & $-0,072(0,892)$ & $0,063(0,906)$ \\
\hline Func. Escolar & $-0,224(0,670)$ & $-0,409(0,421)$ & $0,429(0,396)$ & $0,052(0,922)$ & $-0,182(0,730)$ \\
\hline Escore Total & $-0,174(0,742)$ & $-0,412(0,417)$ & $0,525(0,285)$ & $0,101(0,848)$ & $-0,383(0,454)$ \\
\hline
\end{tabular}

Dor com características nociceptivas

\begin{tabular}{|c|c|c|c|c|c|}
\hline Dor e Dano & $-0,729(0,000)$ & $-0,558(0,000)$ & $-0,171(0,306)$ & $-0,144(0,389)$ & $-0,079(0,639)$ \\
\hline Impacto da Dor & $-0,644(0,000)$ & $-0,637(0,000)$ & $-0,298(0,069)$ & $-0,269(0,102)$ & $-0,174(0,297)$ \\
\hline Controle da Dor & $-0,373(0,021)$ & $-0,323(0,048)$ & $0,031(0,854)$ & $-0,291(0,076)$ & $-0,176(0,290)$ \\
\hline Preocupação I & $-0,163(0,327)$ & $-0,405(0,012)$ & $-0,109(0,516)$ & $0,018(0,912)$ & $-0,104(0,534)$ \\
\hline Preocupação II & $-0,180(0,281)$ & $-0,326(0,046)$ & $-0,149(0,372)$ & $-0,208(0,210)$ & $-0,154(0,357)$ \\
\hline Emoções & $-0,210(0,206)$ & $-0,336(0,039)$ & $-0,220(0,183)$ & $-0,121(0,468)$ & $-0,134(0,423)$ \\
\hline Tratamento & $-0,071(0,674)$ & $-0,059(0,725)$ & $-0,079(0,639)$ & $-0,033(0,844)$ & $-0,045(0,788)$ \\
\hline Comunicação I & $-0,347(0,033)$ & $-0,272(0,099)$ & $-0,037(0,824)$ & $-0,251(0,129)$ & $-0,186(0,264)$ \\
\hline Comunicação II & $-0,416(0,009)$ & $-0,345(0,034)$ & $0,237(0,153)$ & $-0,002(0,988)$ & $-0,126(0,453)$ \\
\hline Func. Físico & $-0,402(0,012)$ & $-0,426(0,008)$ & $-0,209(0,208)$ & $-0,280(0,088)$ & $-0,295(0,072)$ \\
\hline Func. Emocional & $-0,672(0,000)$ & $-0,495(0,002)$ & $-0,175(0,294)$ & $-0,430(0,007)$ & $-0,254(0,124)$ \\
\hline Func. Social & $-0,468(0,003)$ & $-0,458(0,004)$ & $-0,123(0,462)$ & $-0,127(0,448)$ & $-0,212(0,202)$ \\
\hline Func. Escolar & $-0,338(0,038)$ & $-0,284(0,084)$ & $-0,103(0,539)$ & $-0,186(0,265)$ & $-0,041(0,809)$ \\
\hline Escore Total & $-0,706(0,000)$ & $-0,642(0,000)$ & $-0,196(0,238)$ & $-0,291(0,077)$ & $-0,260(0,115)$ \\
\hline
\end{tabular}

Coeficiente de correlação de rô e p-valor do teste de Spearman (alfa 5\%)

\section{Discussão}

Este estudo transversal buscou delinear a dor em crianças e adolescentes com doença falciforme e constatou que a dor com características neuropáticas afetou 13,6 e 26,1\% das amostras compostas por 44 e 46 participantes, respectivamente. Nossos achados permitem considerar que o sistema nervoso central sofre sensibilização durante a fase do desenvolvimento neuropsicomotor, o que justifica a cronicidade da dor em adultos nesta população. Estes dados apontam para a necessidade imperativa de controle farmacológico e não farmacológico da dor em crianças e adolescentes com DF.

As características sociodemográficas das duas amostras confirmam que pessoas com características afrodescendentes são as mais acometidas pela DF. ${ }^{3}$ Em países com Índice de Desenvolvimento Humano (IDH) menor, onde a desigualdade social é maior, esta também é a população que apresenta os piores determinantes sociais da saúde ${ }^{16}$ e, por este motivo, reforça a necessidade de implantação de políticas públicas de proteção e cuidados permanentes para pessoas com DF. 
Quanto à intensidade, a dor na amostra se apresentou de moderada a muito severa com uso frequente de analgésicos, exigindo medidas urgentes de atenção e cuidado. Pode ser considerado desumano não oferecer medidas de proteção, de promoção de saúde e de alívio de sintomas em uma condição que afeta pessoas em situação de vulnerabilidade social. $\frac{16}{}$

Muitos estudos prévios têm referido a presença de dor do tipo neuropática em pessoas com DF. $5,6,10-12$ No entanto, alguns autores referem que a dor nociceptiva é a mais comum nesta população.,.17 Nossos achados demonstram que apesar de menos prevalente, a dor neuropática tem maior impacto em diferentes aspectos reativos e na qualidade de vida. Devido à ausência de um instrumento específico para distinguir o tipo de dor em crianças e adolescentes, os descritores da APPT-P Brasil que correspondem aos descritores do DN-4 discriminativos foram utilizados para a classificação. Verificou-se que a dor com características neuropáticas causam impactos mais negativos do que a nociceptiva.

Observamos que quanto maior a intensidade da dor, mais descritores são utilizados pelas crianças e adolescentes para expressar a dor. Além disso, os que possuem maior intensidade descrevem essa dor com descritores mais avaliativos e afetivos do que sensoriais ou temporais. Esses achados reforçam nossa hipótese de que o tratamento para a dor neuropática deve ser o mais precoce e efetivo possível, uma vez que facilmente afeta aspectos cognitivos e emocionais, aumentando o nível de sofrimento e a chance de cronificação. $\frac{18}{}$

Não foi verificada associação de nenhum dos aspectos da dor com o tipo de hemoglobinopatia, se HbSS ou HbSC. Isto diverge do que tem sido referido em estudos envolvendo adultos. .5 Uma possível explicação para este achado é que a dor pode ter evolução distinta longitudinalmente em cada tipo de DF, levando adultos a se diferenciarem. Além disso, o nível inflamatório pode ser mais relevante do que a anemia para gerar dor aguda, mas não crônica. ${ }^{19}$
Participantes com dor com características neuropáticas apresentaram correlações fortes com a intensidade da dor, com os descritores sensoriais e avaliativos no domínio Dor e Dano do PedQV-DF. Isso confirma que a intensidade da dor é um fator relevante a ser considerado na avaliação desta população nas crises álgicas ${ }^{6}$, mas não devem ser o único aspecto a ser considerado no tratamento. $\frac{18}{}$ Vale ressaltar que também afetaram, na presente amostra, o domínio da comunicação. Como a comunicação implica em diversos aspectos cognitivos e relacionais, a qualidade de vida pode ser muito prejudicada na percepção de crianças e adolescentes. As expectativas que usam como referencial para avaliar a qualidade de vida envolve pares sem DF, o que pode ser um fator de desesperança e até pode causar depressão., 20

Participantes com dor nociceptiva apresentaram correlações fracas entre intensidade da dor e descritores sensoriais nos diferentes domínios da qualidade de vida, exceto em relação ao tratamento. É possível que o fato de estar em um serviço tenham levado a amostra a considerar o risco de prejuízos para o tratamento, influenciando este resultado. Ainda assim, diferentemente do que ocorreu com crianças e adolescentes com dor nociceptiva, a dor neuropática afetou todos os domínios da qualidade de vida. Este achado confirma a hipótese de que esse tipo de dor traz mais prejuízos cognitivos, psicológicos e sociais para a qualidade de vida das crianças e adolescentes afetadas. $\underline{.21-24}$

O tamanho reduzido da amostra e a aplicação em apenas um centro de referência impedem a generalização dos resultados. A baixa qualidade dos prontuários limitou a apresentação de outros dados clínicos relevantes. No entanto, essa pesquisa ajuda a reconhecer a necessidade imperativa de uma avaliação mais acurada a respeito do tipo de dor em crianças e adolescentes para o controle efetivo, especialmente da dor do tipo neuropática. Próximos estudos devem acompanhar longitudinalmente essa população e testar eficácia e segurança de condutas farmacológicas e não-farmacológicas para o controle da dor neuropática nesta população. 


\section{Conclusão}

Podemos concluir que a dor em crianças e adolescentes com doença falciforme se distribui por todo o corpo, apresenta características de dor nociceptiva e neuropática, com os piores prejuízos para os que referem dor do tipo neuropática.

\section{Contribuições das autoras}

Machado RAF e Lima AGB participaram da elaboração do projeto, submissão ao comitê de ética em pesquisa em seres humanos, coleta, tabulação e análise de dados, e revisão de literatura. Carvalho ASS participou da coleta de dados, revisão da literatura e elaboração do banco de dados. Almeida HS participou da revisão da literatura, interpretação dos dados e elaboração do manuscrito. Sá KN participou da elaboração e da coordenação do projeto, interpretação dos resultados, elaboração do artigo e correção da versão final. Todos as autoras aprovaram a versão final do manuscrito submetido e se responsabilizam pela veracidade dos dados.

\section{Conflitos de interesses}

Nenhum conflito financeiro, legal ou político envolvendo terceiros (governo, empresas e fundações privadas, etc.) foi declarado para nenhum aspecto do trabalho submetido (incluindo, mas não se limitando a subvenções e financiamentos, participação em conselho consultivo, desenho de estudo, preparação de manuscrito, análise estatística, etc.).

\section{Referências}

1. Ministério da Saúde (Brasil), Secretaria de Atenção à Saúde, Departamento de Atenção Especializada. Doença falciforme: condutas básicas para tratamento [Internet]. Brasília: Ministério da Saúde; 2012. Disponível em: https://bvsms.saude.gov.br/bvs/ publicacoes/doenca_falciforme_condutas_basicas.pdf

2. Silva RBP, Ramalho AS, Cassoria RMS. A anemia falciforme como problema de Saúde Pública no Brasil. Rev. Saúde Pública, 1993;27(1):54-8. https://doi.org/10.1590/S003489101993000100009

3. Felix AA, Souza HM, Ribeiro SBF. Aspectos epidemiológicos e sociais da doença falciforme. Rev Bras Hematol Hemoter. 2010;32(3):203-8. https://doi.org/10.1590/S1516$\underline{84842010005000072}$
4. Silva WS, Oliveira RF, Ribeiro SB, Silva IB, Araújo EM, Baptista AF. Screening for Structural Hemoglobin Variants in Bahia, Brazil. Int J Environ Res Public Health. 2016;13(2):13-8. https://doi. org/10.3390/ijerph13020225

5. Ballas SK. Current issues in Sickle Cell Pain and Its Management. Hematology Am Soc Hematol Educ Program. 2007;(1):97-105. https://doi.org/10.1182/asheducation-2007.1.97

6. Ballas SK, Gupta K, Adams-Graves P. Sickle cell pain: A critical reappraisal. Blood. 2012;120(18):3647-56. https://doi. org/10.1182/blood-2012-04-383430

7. Gilron I, Watson CPN, Cahill CM, Moulin DE. Neuropathic pain: a practical guide for the clinician. CAMAJ. 2006;175(3):265-75. https://doi.org/10.1503/cmaj.060146

8. Treede RD, Campbell JN, Cruccu G, Dostrovsky JO, Griffin JW, Hansson P, et al. Neuropathic pain: Redefinition and a grading system for clinical and research purposes. Neurology. 2008;70(18):1630-5. https://doi.org/10.1212/01. $\underline{w n l .0000282763 .29778 .59}$

9. Bakshi N, Lukombo I, Shnol H, Belfer I, Krishnamurti L. Psychological characteristics and pain frequency are associated with experimental pain sensitivity in pediatric patients with sickle cell disease. Pain. 2017;18(10):1216-28. https://doi.org/10.1016/j. jpain.2017.05.005

10. Brandow AM, Farley RA, Dasgupta M, Hoffmann RG, Panepinto JA. The Use of Neuropathic Pain Drugs in Children with Sickle Cell Diseases is Associated with Older Age, Female Gender and Longer Length of Hospital Stay. J Pediatr Hematol Oncol. 2015;37(1):10-5. https://dx.doi.org/10.1097\%2FMPH.0000000000000265

11. Ballas SK, Darbari DS. Neuropathy, neuropathic pain, and sickle cell disease. Am J Hematol. 2013;88(11):927-9. https://doi. org/10.1002/ajh.23575

12. Antunes FD, Propheta VGS, Vasconcelos HA, Cipolotti R. Neuropathic pain in patients with sickle cell disease: a crosssectional study assessing teens and young adults. Ann Hematol. 2017;96(7):1121-5. https://doi.org/10.1007/s00277-017-2984-z

13. Jacob E, Mack AK, Savedra M, Cleve LV, Wilkie DJ. Adolescent Pediatric Pain Toll (APPT) for Multidimensional Measurementof Pain in Children and Adolescents. Pain Manag Nurs. 2014;15(3):694-706. https://dx.doi.org/10.1016\%2Fj. pmn.2013.03.002

14. Santos JG, Brito JO, Andrade DC, Kaziyama VM, Ferreira KA, Souza I, et al. Translation to Portuguese and validation of the Douleur Neuropathique 4 questionnaire. J Pain. 2010;11(5):48490. https://doi.org/10.1016/j.jpain.2009.09.014 
15. Pereira LMS. Desenvolvimento de um Instrumento Multidimensional para Avaliação de Dor em Crianças a partir de Descritores Observados em Narrativas Infantis [tese de doutorado] [Internet]. Recife: Universidade Federal de Pernambuco; 2015. Disponível em: https://repositorio.ufpe.br/ handle/123456789/15485

16. Marmot M. Social determinants of health inequalities. Lancet. 2005;365(9464):1099-104. https://doi.org/10.1016/s0140$\underline{6736(05) 71146-6}$

17. Cataldo G, Rajput S, Gupta K, Simone DA. Sensitization of nociceptive spinal neurons contributes to pain in a transgenic model of sickle cell disease. Pain. 2015;156(4):722-30. https://doi. org/10.1097/j.pain.0000000000000104

18. Antunes FD, Silva Junior CL, Cerqueira KS, Faro ML, Cipolotti R. Screening for neuropathic pain in patients with sickle cell disease: Is a single assessment scale sufficient? Orphanet J Rare Dis. 2019;14(108). https://doi.org/10.1186/s13023-019-1082-9

19. Guarda CC, Yahouédéhou SCMA, Santiago RP, Neres JSDS, Fernandes CFL, Aleluia MM, et al. Sickle cell disease: A distinction of two most frequent genotypes ( $\mathrm{HbSS}$ and $\mathrm{HbSC}$ ). PLoS One. 2020;15(1):e0228399. https://dx.doi.org/10.1371\%2Fjournal. pone.0228399
20. Santos LFO, Guimarães MW, Baptista AF, Sá KN. Impact of neuropathic pain on quality of life in adults with sickle cell disease: observational study. Hematol, Transfus Cell Ther. 2020. https:// doi.org/10.1016/j.htct.2020.03.010

21. Hardy SJ, Bills SE, Wise SM, Hardy KK. Cognitive Abilities Moderate the Effect of Disease Severity on Health-Related Quality of Life in Pediatric Sickle Cell Disease. J Pediatr Psychol. 2018;43(8):882-94. https://doi.org/10.1093/jpepsy/jsy019

22. Kambasu DM, Rujumba J, Lekuya HM, Munube D, Mupere E. Health-related quality of life of adolescents with sickle cell disease in sub-Saharan Africa: a cross-sectional study. BMC Hematol. 2019 May 14;19:9. https://doi.org/10.1186/s12878-019-0141-8

23. Ludwig NN, Sil S, Khowaja MK, Cohen LL, Dampier C. Executive Functioning Mediates the Relationship Between Pain Coping and Quality of Life in Youth With Sickle Cell Disease. J Pediatr Psychol. 2018;43(10):1160-9. https://doi.org/10.1093/jpepsy/jsy057

24. Román ME, Highland J, Retherford D, Pan AY, Panepinto JA, Brandow AM. Neuropathic pain is associated with poor healthrelated quality of life in adolescentes with sickle cell disease: $A$ preliminar report. Pediatr Blood Cancer. 2020;67(12):e28698. https://doi.org/10.1002/pbc.28698 